\title{
A Simple and Cost-effective Approach for Salt Tolerance Evaluation in Cowpea (Vigna unguiculata) Seedlings
}

\author{
Waltram Ravelombola \\ Department of Horticulture, University of Arkansas, Fayetteville, AR 72701
}

Jun Qin

Department of Horticulture, University of Arkansas, Fayetteville, AR 72701; and Hebei Academy of Agricultural and Forestry Sciences, Shijiazhuang, Hebei 050031, China

Yuejin Weng
Department of Horticulture, University of Arkansas, Fayetteville, AR 72701

Beiquan Mou ${ }^{1}$

Crop Improvement and Protection Research Unit, U.S. Department of Agriculture, Agricultural Research Service (USDA-ARS), 1636 E. Alisal Street, Salinas, CA 93905

\section{Ainong Shi ${ }^{1}$ \\ Department of Horticulture, University of Arkansas, Fayetteville, AR 72701}

Additional index words. germplasm, salinity

\begin{abstract}
Little has been done with respect to breeding for salt-tolerant cowpea (Vigna unguiculata) cultivars despite of salt stress being a growing threat to cowpea production. Seedling stage is one the most susceptible stages to salt stress in cowpea. Establishing a streamlined methodology for rapidly screening a large number of genotypes will significantly contribute toward enhancing cowpea breeding for salt tolerance. Therefore, the objective of this study was to establish and validate a simple approach for salt tolerance evaluation in cowpea seedlings. A total of 30 genotypes including two controls (PI582468, a salt-tolerant genotype, and PI255774, a salt-sensitive genotype) were greenhouse-grown under $0 \mathrm{~mm}$ and $200 \mathrm{~mm} \mathrm{NaCl}$. A total of 14 above-ground traits were evaluated. Results revealed: (1) significant differences were observed in average number of dead plants per pot, leaf injury scores, relative salt tolerance (RST) for chlorophyll, plant height, and leaf and stem biomass among the 30 genotypes; (2) all PI255774 plants were completely dead, whereas those of PI582438 were fully green after 2 weeks of salt stress, which validated this methodology; (3) RST for chlorophyll content was highly correlated with number of dead plants and leaf injury scores; (4) RST for leaf biomass was moderately correlated with number of dead plants and leaf injury scores; and (5) RST in plant height was poorly correlated with number of dead plants and leaf injury scores Therefore, less number of dead plants per pot, high chlorophyll content, and less leaf injury scores were good criteria for salt tolerance evaluation in cowpea. This study provided a simple methodology and suggested straightforward criteria to evaluate salt tolerance at seedling stage in cowpea.
\end{abstract}

Cowpea [Vigna unguicalata (L.) Walp.] is a diploid legume species $(2 n=2 x=22)$ widely grown in Africa, Asia, the Middle East, southern Europe, southern and western United States, and Central and South America. Worldwide cowpea production is estimated to be 5.4 million tons of cowpea grain annually and Africa is the leading producer (Olufajo 2012). Cowpea is cultivated on more than 14

Received for publication 20 Mar. 2019. Accepted for publication 16 Apr. 2019.

This work is supported, in part, by the U.S. Department of Agriculture National Institute of Food and Agriculture Hatch project accession number 1002423

${ }^{1}$ Corresponding authors. E-mail: Beiquan.Mou@, ARS.USDA.GOV or ashi@uark.edu.
Salinity is one of the major limiting factors that have been constraining agricultural production globally (Allakhverdiev et al., 2000). In croplands, salinity is due to an undesirable increase in the concentration of cations such as $\mathrm{K}^{+}, \mathrm{Mg}^{2+}, \mathrm{Ca}^{2+}$, and $\mathrm{Na}^{+}$ and anions such as $\mathrm{NO}_{3-}, \mathrm{HCO}_{3-}, \mathrm{SO}_{4}{ }^{2-}$, and $\mathrm{Cl}^{-}$according to Wallender and Tanji (2011). Salinity due to sodium chloride $(\mathrm{NaCl})$ has been predominant (Ayers and Westcot, 1985); hence, tolerance to this type of salt was reported in this current investigation. The estimate of cropland areas facing salinity was more than 19.6 million hectares in the United States (Shannon 1997). Costs related to problems imposed by salinity on agriculture were 12 billion US dollars (Läuchli and Lüttge, 2002). Multiple factors such as rock weathering, deforestation, poor quality of irrigation water, and inadequate fertilization practices can worsen salinity on cultivated lands (Omami and Hammes, 2006).

Studies have shown that salt stress can cause serious concerns to cowpea production. Cowpea germination has been shown to be unfavorably affected by salt stress (Zahedi et al., 2012). Salt-stressed cowpea plants exhibited a reduced plant growth and vigor (Mini et al., 2015). Salt stress can impair plant physiology, photosynthesis, and absolutely important functions such as cell extension and division (Maas and Hoffman, 1977). These aforementioned factors could lead to a significant cowpea yield reduction (Dutta and Bera, 2014). Breeding for cowpea salt-tolerant cultivars is one of the most affordable solutions to tackle these issues. However, few studies have focused on addressing salt stress in cowpea in efforts to adequately providing breeders with critical information on the tolerance of cowpea genotypes to salinity.

Phenotyping is a substantial process in screening genotypes for a particular trait of interest. It is usually a labor-intensive, timeconsuming, and a costly task to undertake for plant breeders. The increasing needs for accurate and less expensive phenomics require the establishment of a fast and costeffective methodology. To the best of our knowledge, there is no reported methodology on salt tolerance phenotyping in cowpea. Salt phenotyping can be carried in fields. However, the uncontrolled factors such as differences in soil fertility, temperature, and transpiration could increase the unexplained part of the variation in salt tolerance among cowpea genotypes, thus leading to biased conclusions (Pathan et al., 2007). Hydroponic system has long been considered the ideal approach for salt tolerance phenotyping in crops. However, this requires adequate facilities and specialized skills (An et al., 2001), which could significantly increase the phenotyping cost.

Since cowpea is cultivated predominantly in developing countries, a methodology that can be applied in these areas in which funds and facilities are very limited would be most helpful. In addition, the screening methodology should allow for a rapid and accurate salt 
tolerance phenotyping of a large number of genotypes to be efficient. Seedling stage is one of the most vulnerable stages to salt stress in cowpea (Win and Oo, 2015). Suggesting a strategy that can help cowpea breeders select for salt-tolerant genotype at seedling stage is therefore important and can also assist with at least narrowing down the number of genotypes for salt tolerance screening at a later stage. Therefore, the objective of this study was to establish an approach that can be easily applied for salt tolerance phenotyping for cowpea at seedling stage.

\section{Materials and Methods}

Plant materials. A total of 30 cowpea accessions originating from 13 countries were used in this study (Table 1). These genotypes were PIs from the United States

Table 1. List of 30 cowpea accessions including two accessions (PI255774 and PI582468) used as control.

\begin{tabular}{|c|c|c|}
\hline Accession & Plant name ${ }^{z}$ & Origin $^{z}$ \\
\hline$\overline{\text { PI190191 }}$ & TVu 1557 & Mexico \\
\hline PI229734 & CHESH BOLBOLI LUBI & Iran \\
\hline PI255774y & TVu 2428 & Nigeria \\
\hline PI291140 & NEGRO & Australia \\
\hline PI292898 & TVu 1890 & Hungary \\
\hline PI293469 & BROWN CROWDER & United States \\
\hline PI293586 & WILT RESISTANT BLACKEYE & $N / A^{x}$ \\
\hline PI349674 & ALOOMBA & Australia \\
\hline PI354832 & P 1350 & India \\
\hline PI354835 & P 1353 & India \\
\hline PI354860 & P 1387 & India \\
\hline PI354864 & P 1392 & India \\
\hline PI354865 & P 1393 & India \\
\hline PI582352 & UCR 154 & Saudi Arabia \\
\hline PI582353 & UCR 155 & Saudi Arabia \\
\hline PI582366 & UCR 191 & India \\
\hline PI582368 & UCR 193 & India \\
\hline PI582402 & PITIUBA & Brazil \\
\hline PI582428 & LAURA B & Trinidad and Tobago \\
\hline PI582468 ${ }^{\mathrm{y}}$ & UCR 347 & $N / A^{x}$ \\
\hline PI582551 & UCR 1004 & Botswana \\
\hline PI582573 & KVu 23 & Kenya \\
\hline PI582697 & UCR 1176 & Botswana \\
\hline PI582812 & UCR 794 & Botswana \\
\hline PI582852 & UCR 935 & Botswana \\
\hline PI582863 & UCR 1017 & Botswana \\
\hline PI583232 & UCR 3317 & Senegal \\
\hline PI664515 & Bettergreen & United States \\
\hline PI664517 & Bettergro Blackeye & United States \\
\hline PI664524 & Green Dixie Blackeye & United States \\
\hline
\end{tabular}

${ }^{\mathrm{Z}}$ Plant name and country of origin were based on the information found at https://npgsweb.ars-grin.gov/ gringlobal/descriptors.aspx?

${ }^{\mathrm{y}} \mathrm{PI} 255774$ is a salt-sensitive genotype, whereas PI582468 is a salt-tolerant one as previously reported (Ravelombola et al., 2017). These genotypes were used to validate the methodology.

${ }^{\mathrm{x}}$ Information was not available.

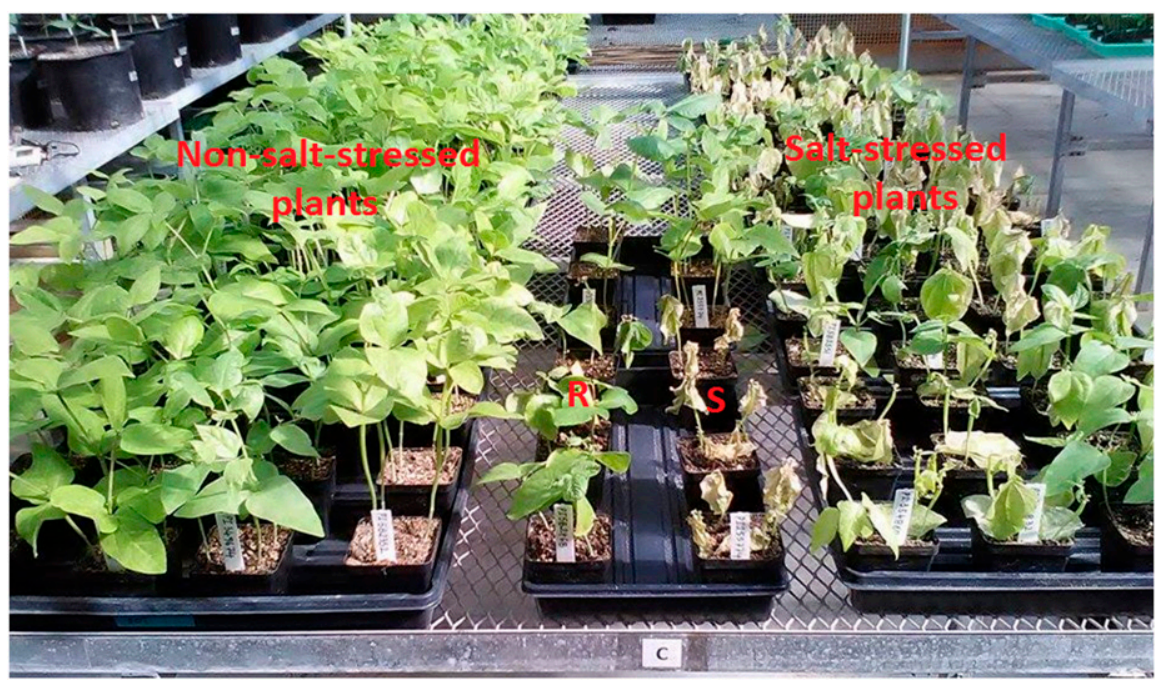

Fig. 1. Phenotyping of salt tolerance in cowpea at seedling stage $14 \mathrm{~d}$ of salt stress. (R) Salt-tolerant genotype, PI582468, and (S) salt-sensitive genotype, PI255774, used as controls. Salt treatment was conducted by irrigating each plastic pot from the bottom.
Department of Agriculture (USDA) Germplasm Resources Information Network cowpea germplasm accessions. Cowpea seeds were obtained from the USDA Plant Genetic Resources Conservation Unit at Griffin, GA. Seeds were increased in the summer of 2017 at the University of Arkansas, Fayetteville, AR. Of the 30 cowpea genotypes, PI582468 (salt-tolerant) and PI255774 (salt-susceptible) (Ravelombola et al., 2017), were used as control to validate the methodology. At the end of the experiment, the two extreme genotypes from the remaining 28 along with the aforementioned controls were independently repeated from the current investigation to further validate the results.

Growth conditions and experiment design. The experiment was conducted in the greenhouse of Harry R. Rosen Alternative Pest Control of the University of Arkansas, Fayetteville, AR (Fig. 1). Temperatures in the greenhouse were $26^{\circ} \mathrm{C} / 21^{\circ} \mathrm{C}$ (day/night) and daylight length was $14 \mathrm{~h}$. Cowpea plants were established in pots previously filled up with $100 \mathrm{~g}$ Sunshine Natural \& Organic (Agawam, MA).

Holes were designed at the bottom of each pot, and paper was placed at the bottom of each pot as well to prevent soil medium from leaking during irrigation. In each pot, six to eight seeds were sown. When cowpea plants emerged, four vigorous and uniform plants were kept. One week after plant emergence, plants were fertilized with an application of a solution of $50 \mathrm{~mL}$ of Miracle-Gro fertilizers (Scotts Miracle-Gro, Detroit, MI) in each pot, and the same fertilizer was weekly applied to all pots until the end of the experiment.

Each genotype was planted in six pots, of which three pots were salt-treated, whereas the remaining three pots were irrigated with deionized water. Pots were placed on rectangular plastic trays to facilitate the irrigation. Salt $(\mathrm{NaCl})$ treatment began when the first trifoliate leaf began to expand (V1 stage) (Fehr et al., 1971). Salt concentration was $200 \mathrm{~mm} \mathrm{NaCl}$ as described previously (Abeer et al., 2015; Ashebir et al., 2013; Paul et al., 2011; Ravelombola et al., 2017).

We conducted a preliminary test involving only the two accessions used as control under the aforementioned $\mathrm{NaCl}$ concentration and used the current screening methodology and found that all plants from the salt-tolerant genotype (PI582468) were fully green and that of from the salt-susceptible genotype (PI255774) were completely dead after $14 \mathrm{~d}$ of salt stress (Fig. 2). Salt concentration was obtained by dissolving a total of $11.7 \mathrm{~g}$ of $\mathrm{NaCl}$ powder of Science Company (Lakewood, CO) in $1 \mathrm{~L}$ of deionized water.

Irrigation was performed by supplying either deionized water or salt solution to the plastic trays described previously. Irrigation was achieved such that pots were soaked with solution up to two third of pot height. The solution was kept within the plastic trays for $2 \mathrm{~h}$ every day. The treatment was conducted until the susceptible check (PI255774) was completely dead. This irrigation strategy was key, since it assisted cowpea roots with being 
permanently exposed to salt ions, which could lead to salt stress. In addition, doing so could limit within pot variation due to the differences in soil-root transmission if the rhizosphere was not completely soaked with solution. This irrigation approach has been proven to be efficient in salt tolerance screening in other crops (Ledesma et al., 2016).

The experiment design was completely randomized design with three replications per genotype. Factors include the set of 30 genotypes evaluated for salt tolerance. Genotypes were assumed to have fixed effects whereas the replications a random effect.

Measurements. Measurements were taken when the susceptible check was completely dead. Leaf injury was assessed based on a 1 to 7 scale (Fig. 3) $(1=$ healthy plants, $2=$ first sign of leaf chlorosis, $3=$ expansion of chlorosis on leaf surface, $4=$ totally chlorotic leaf, 5 = first sign of necrosis, $6=$ expansion

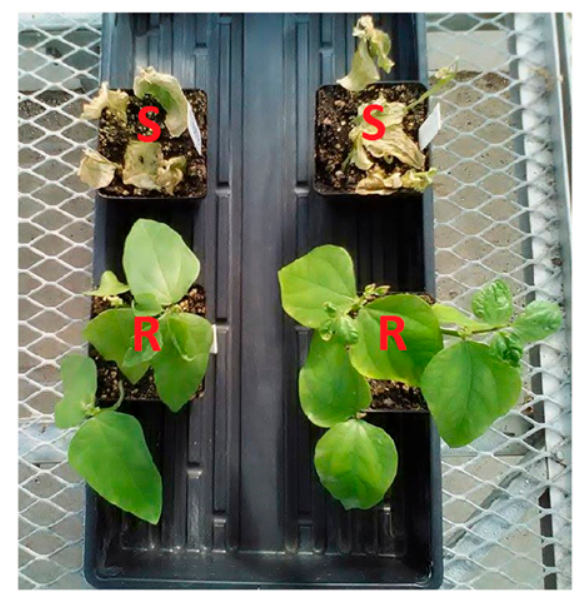

Fig. 2. Differences in aboveground traits between salt-tolerant and salt-sensitive genotypes $14 \mathrm{~d}$ of salt stress. $\mathrm{R}=$ salt-resistant; $\mathrm{S}=$ saltsensitive. of necrosis on leaf surface, and $7=$ completely dead plants).

The number of dead plants per pots was counted. Plant height (from the bottom part to growing point) for both non-stressed and saltstressed plants was measured on per plant basis. RST for plant height, described as the ratio between plant height under stress and non-stress conditions, was computed (Saad et al., 2014). Data on fresh leaf biomass under non-stress and stress conditions were collected and RST for fresh leaf biomass was calculated. Fresh stem biomass under nonstress and stress conditions along with the RST for fresh stem biomass were assessed as well. Leaf chlorophyll was measured using a chlorophyll SPAD-502 Plus (Spectrum Technologies Inc., Plainfield, IL) for non-stressed and salt-stressed plants and RST for chlorophyll content was computed.

Data analysis. Data were analyzed using PROC MIXED of SAS v.9.4 (SAS Institute Inc., Cary, NC). Mean separation was done using a protected least significant difference (LSD) procedure at $\alpha=0.05$.

LSD procedure was described as LSD $=\mathrm{t}_{\alpha / 2}$ $\sqrt{2}$ MSError/n, where $t_{\alpha / 2}$ was a critical value from the $t$-table with $\mathrm{df}($ SSError $)=$ Number of observations-Number of genotypes, and $\mathrm{n}=$ number of replications. Person's correlation coefficients and descriptive statistics were computed using JMP Genomics 7 (SAS Institute Inc., Cary, NC). Graphs and path analysis were established using the packages 'MASS' and 'Network' of R 3.1.1.

\section{Results}

Number of dead plants. The average number of dead plants per pot was evaluated for each genotyped at $14 \mathrm{~d}$ of salt stress. At that time, all plants from the susceptible check, PI255774, were completely dead, whereas those from the tolerant check, PI582468, were fully green (Fig. 1). The

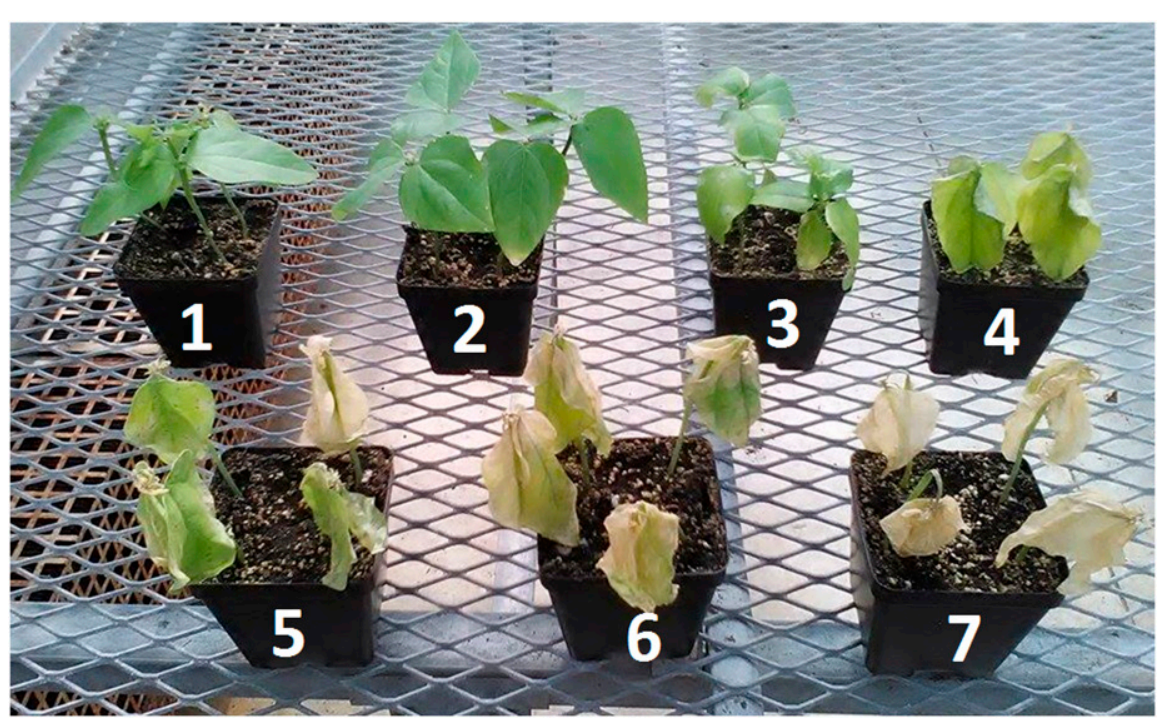

Fig. 3. Foliar injury due to salt stress: $1=$ healthy plants, $2=$ first sign of leaf chlorosis, $3=$ expansion of chlorosis on leaf surface, $4=$ totally chlorotic leaf, $5=$ first sign of necrosis, $6=$ expansion of necrosis on leaf surface, and $7=$ completely dead plants. number of dead plants varied from 0.00 to 4.00 dead plants per pot, with an average of 3.18 dead plants per pot and an SD of 1.20. Distribution of number of dead plants per pot was left-skewed (Fig. 4). Analysis of variance (ANOVA) revealed significant differences in number of dead plants among the 30 genotypes $(\mathrm{F}$-value $=18.50, P$ value $<$ 0.0001 ) (Table 2). The genotypes having less than two dead plants per pot were PI582468 (0.00), PI349674 (0.00), PI582812 (1.00), PI293469 (1.33), and PI190191 (1.67) (Supplemental Table 1). All plants from the genotypes PI664517, PI664515, PI582852, PI582573, PI582551, PI582428, PI582402, PI354860, PI354835, PI293586, PI291140, PI255774, and PI229734 were completely or almost dead at $14 \mathrm{~d}$ of salt stress.

To further validate the results, the two checks (PI582468 and PI255774) along with PI349674, having all plants being fully green at $14 \mathrm{~d}$ of salt stress, and PI582573, showing severe chlorosis at that time, were independently repeated from the previous trial. The results from the repeated experiment were consistent with the previous one as shown in Fig. 5. The tolerant control was fully green, whereas the susceptible check was completely dead. In addition, none of the plants from the genotypes PI349674 were dead, whereas those of PI582573 were chlorotic (Fig. 5), indicating that this current methodology could provide replicability of salt tolerance or salt susceptibility over time, hence stable and useful for investigating potential major genes affecting salt tolerance in cowpea.

Leaf injury score. Leaf injury was scored based on a 1 to 7 scale depending on leaf greenness and chlorosis. Leaf injury scores were in the range of 1.33 to 7.00 , with an average of 5.66 and an SD of 1.52, indicating a large variation of leaf injury score among the genotypes. Distribution of leaf injury scores was left-skewed (Fig. 4). A significant difference in leaf injury scores was found among the 30 genotypes (F-value $=30.58$, $P$ value $<0.0001$ ) (Table 2). Leaf score injury for tolerant control was 1.33 , whereas the susceptible scored 7.00, suggesting that this methodology permitted a clear distinction between the two controls. In addition to the tolerant check, PI349674 (1.67), PI582812 (3.33), and PI190191 (3.50) scored the least (Supplemental Table 1), suggesting that these genotypes were salt-tolerant. Greatest leaf injury score was recorded for the genotypes PI291140 (6.50), PI582368 (6.50), PI582863 (6.50), PI293586 (6.60), PI354865 (6.67), PI664515 (6.67), PI292898 (6.77), PI664517 (6.83), PI582428 (7.00), PI582573 (7.00), and PI582852 (7.00) (Supplemental Table 1), which suggested that these genotypes were susceptible to salt stress. Leaf scoring was consistent in the repeated trials involving the controls along with PI349674 and PI582573, indicating that the methodology was stable.

Chlorophyll (SPAD). Chlorophyll (SPAD) was assessed in both non-salt-treated and salt-stressed cowpea plants, and RST for chlorophyll content (SPAD) was calculated. 
Chlorophyll content of plants without salt stress was greater than those under salt stress at $14 \mathrm{~d}$ of salt stress, indicating that salt stress significantly affected leaf chlo-

\section{Number of dead plants per pot}

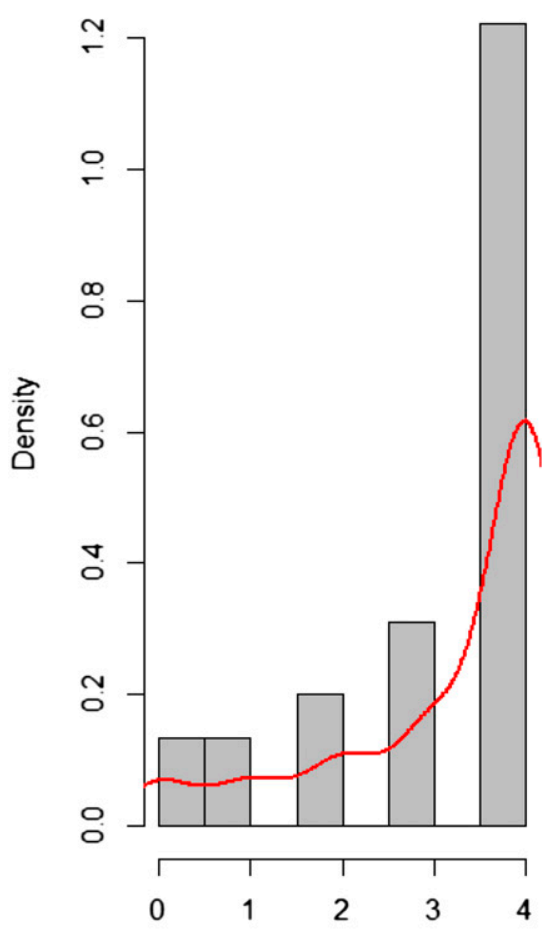

Average number of dead plants per pot rophyll (Fig. 6). Distributions of chlorophyll content in leaves of salt-stressed and non-stress plants and RST were about normally distributed (Fig. 6). For the salt- stressed plants, chlorophyll content varied from 2.00 to 26.07 , with a mean of 13.07 and an SD of 5.53, at $14 \mathrm{~d}$ of salt stress. Significant difference in chlorophyll content was found $(\mathrm{F}$-value $=9.27, P$ value $<$ 0.0001) (Table 2). Chlorophyll content (SPAD) of the tolerant check (PI582468) was 26.07, whereas that of the susceptible check was 5.83 (Supplemental Table 1). The well-performing genotypes under salt stress in addition to the tolerant check were PI349674 (24.10), PI582812 (21.60), PI293469 (19.43), PI664524 (18.70), and PI190191 (18.43) (Supplemental Table 1), indicating that these genotypes were tolerant to salt stress. The least performers in terms of chlorophyll content besides the susceptible check were PI354835 (9.90), PI293586 (9.77), PI582368 (9.73), PI664517 (9.17), PI292898 (8.67), PI582852 (8.47), PI582573 (4.30), and PI582428 (2.00) (Supplemental Table 1).

RST for chlorophyll content was the ratio between chlorophyll content of salt-stressed and non-stressed plants. The greater the RST was, the more salt-tolerant the genotype was. RST for chlorophyll content ranged from 0.08 to 0.97 , with an average of 0.47 and an SD of 0.19. Significant differences in RST among the genotypes were found $(\mathrm{F}$-value $=$ 7.62, $P$ value $<0.0001$ ) (Table 2 ). The tolerant check had a RST value of 0.97 , whereas the susceptible check had a relative salt value of 0.21 . The most salt-tolerant genotypes based on RST for chlorophyll content in addition to the tolerant check were PI349674 (0.75), PI293469 (0.75), PI664524 (0.67), and PI582812 (0.67) (Supplemental Table 1). Those having the lowest RST value

Fig. 4. Distributions of the average number of dead plants per pot and leaf injury score.

Table 2. ANOVA table for traits evaluated for salt tolerance phenotyping at seedling stage.

\begin{tabular}{|c|c|c|c|c|c|c|}
\hline$\overline{\text { Phenotype }^{z}}$ & Source & $\overline{\mathrm{DF}}$ & Sum of squares & Mean square & F value & $\operatorname{Pr}>F$ \\
\hline Dead plants & Accession & 29 & 125.16 & 4.32 & 18.50 & $<0.0001$ \\
\hline \multirow[t]{2}{*}{ Leaf injury score } & Accession & 29 & 201.61 & 6.95 & 30.58 & $<0.0001$ \\
\hline & Error & 60 & 13.64 & 0.23 & & \\
\hline Chlorophyll_NonStress & Error & 60 & 338.59 & 5.64 & & \\
\hline \multirow[t]{2}{*}{ Chlorophyll_Stress } & Accession & 29 & 2659.46 & 91.71 & 9.27 & $<0.0001$ \\
\hline & Error & 60 & 593.45 & 9.89 & & \\
\hline \multirow{2}{*}{ Height_NonStress } & Accession & 29 & 636.48 & 21.95 & 27.19 & $<0.0001$ \\
\hline & Error & 60 & 48.43 & 0.81 & & \\
\hline \multirow[t]{2}{*}{ Height_Stress } & Accession & 29 & 174.36 & 6.01 & 11.08 & $<0.0001$ \\
\hline & Error & 60 & 32.56 & 0.54 & & \\
\hline \multirow[t]{2}{*}{ Height_RST } & Accession & 29 & 0.39 & 0.01 & 4.01 & $<0.0001$ \\
\hline & Error & 60 & 0.20 & 0.003 & & \\
\hline LeafBiomass_NonStress & Accession & 29 & 38.92 & 1.34 & 11.99 & $<0.0001$ \\
\hline \multirow[t]{2}{*}{ StemBiomass_NonStress } & Accession & 29 & 18.58 & 0.64 & 15.36 & $<0.0001$ \\
\hline & Error & 60 & 2.50 & 0.04 & & \\
\hline \multirow[t]{2}{*}{ StemBiomass_Stress } & Accession & 29 & 5.36 & 0.18 & 16.88 & $<0.0001$ \\
\hline & Error & 60 & 0.66 & 0.01 & & \\
\hline \multirow[t]{2}{*}{ StemBiomass_RST } & Accession & 29 & 1.42 & 0.05 & 5.13 & $<0.0001$ \\
\hline & Error & 60 & 0.57 & 0.01 & & \\
\hline
\end{tabular}

${ }^{\mathrm{z}}$ Phenotypes were collected at $14 \mathrm{~d}$ of salt stress on a per plant basis. The susceptible check was completely dead at $14 \mathrm{~d}$ of salt stress.

${ }^{\mathrm{y}}$ Relative salt tolerance (RST) was the ratio between the phenotypic values under salt stress and without salt stress.

ANOVA $=$ analysis of variance. 


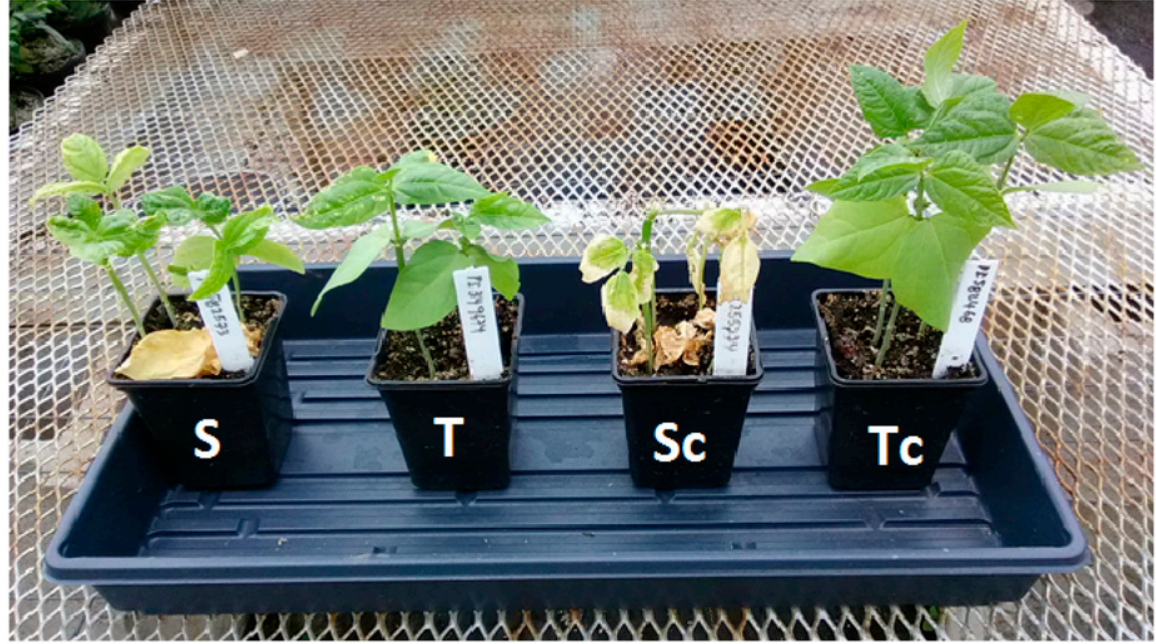

Fig. 5. Independent replicated trial involving the tolerant check (Tc: PI582468), the susceptible check (Sc: PI255774), and one of the salt-tolerant genotypes (T: PI349674) and salt-susceptible ones (S: PI582573) as identified in the previous experiment. The results from the independent replicated trials showed that the current methodology was stable.
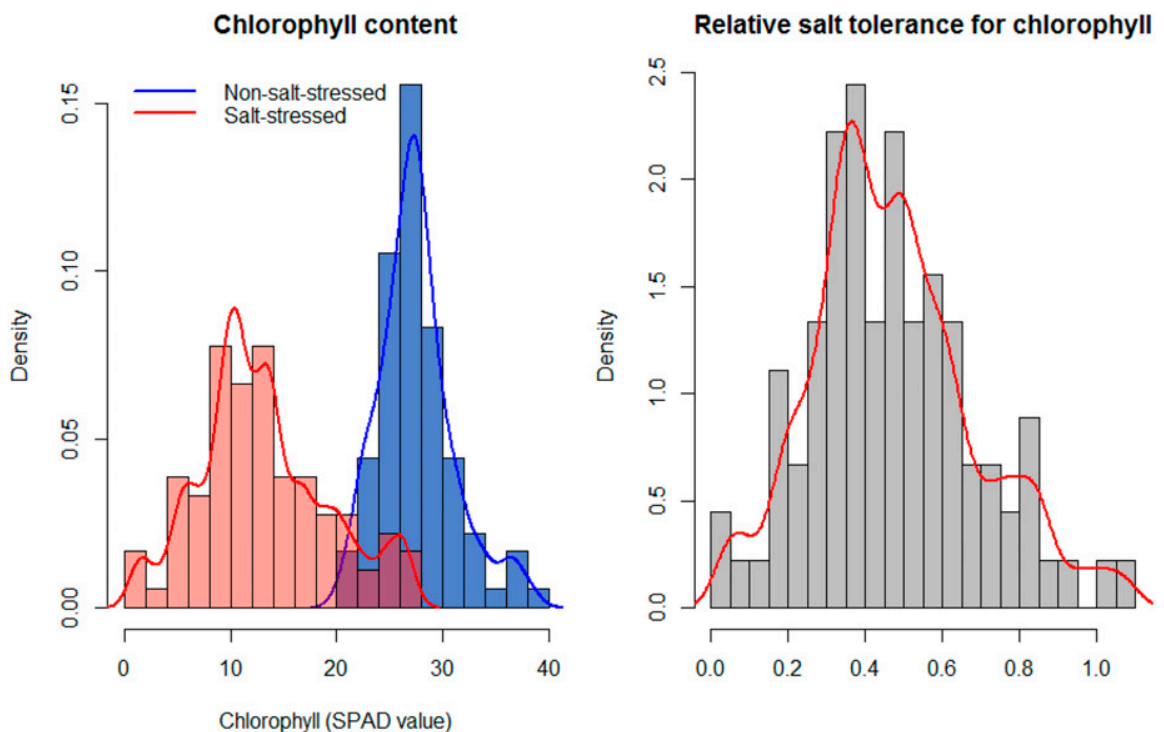

Fig. 6. Distributions of chlorophyll content of non-salt-stressed and salt-stressed plants, and relative salt tolerance for chlorophyll content.

besides the susceptible check were PI292898 (0.34), PI664515 (0.33), PI664517 (0.33), PI582852 (0.31), PI582573 (0.16), and PI582428 (0.08) (Supplemental Table 1).

Plant height. Plant height of salt-stressed and non-stressed plants was measured at $14 \mathrm{~d}$ of salt stress when the susceptible check was completely dead. Salt stress significantly reduced plant height (Fig. 1). Plant height of non-stressed plants varied from 10.43 to $20.00 \mathrm{~cm}$, with an average of $14.70 \mathrm{~cm}$ and an SD of $2.70 \mathrm{~cm}$. That of stressed plants ranged between 5.87 and $11.80 \mathrm{~cm}$, with a mean of $8.18 \mathrm{~cm}$ and an SD of $1.42 \mathrm{~cm}$. Plant height under both conditions was about normally distributed (Fig. 7). Significant differences in plant height without saltstress $(\mathrm{F}$-value $=27.19, P$ value $<0.0001)$ and under salt stress $($ F-value $=11.08, P$ value $<0.0001$ ) (Table 2) were identified. plant height could not be accurately evaluated using the current methodology.

Fresh leaf biomass weight. Leaf biomass was measured when the susceptible check was completely dead. Leaf biomass of plants without salt stress was about normally distributed, whereas that of salt-stressed plants was right-skewed (Fig. 8).

Under non-stress conditions, average leaf biomass per plant ranged from $1.51 \mathrm{~g}$ to 4.69 $\mathrm{g}$, with an average of $2.55 \mathrm{~g}$ and an SD of 0.67 g. Under salt treatment, leaf biomass varied between 0.15 and $1.39 \mathrm{~g}$, with an average of $0.77 \mathrm{~g}$ and an SD of $0.40 \mathrm{~g}$. In addition, correlation analysis showed week association $(r=0.15)$ between leaf biomass under salt stress and non-stress conditions, indicating that the observed variation in leaf biomass under salt stress among the genotypes was more likely to be associated with a genetic response specific to the genotype rather than being correlated with an adaptation due to plant morphology. ANOVA showed significant differences in leaf biomass under salt stress among the genotypes ( $\mathrm{F}$-value $=0.47$, $P$ value $<0.0001$ ) (Table 2). Genotypes having the heaviest leaf biomass under salt conditions were PI664524 (1.50 g), PI582551 (1.39 g), PI349674 (1.38 g), PI582352 (1.30 g), PI293469 (1.25 g), and PI582468 (1.18 g) (Supplemental Table 2). Those having the lightest leaf biomass under salt stress were PI582368 (0.36 g), PI354865 (0.35 g), PI582428 (0.30 g), PI664515 (0.24 g), PI582573 (0.24 g), PI229734 (0.24 g), and PI255774 (0.15 g) (Supplemental Table 2).

RST for leaf biomass had a right-skewed distribution (Fig. 8). Leaf biomass RST varied from 0.05 to 0.71 , with a mean of 0.32 and an SD of 0.18. RST for leaf biomass was statistically significantly different among the genotypes $(\mathrm{F}$-value $=5.64, P$ value $<$ $0.0001)$. Genotypes having the greatest RST for leaf biomass were PI293469 (0.71), PI582551 (0.65), PI349674 (0.60), PI354864 (0.54), and PI354860 (0.51) (Supplemental Table 2). The lowest RST for leaf biomass was recorded for PI229734 (0.10), PI582428 (0.09), PI255774 (0.08), and PI664515 (0.05) (Supplemental Table 2)

Fresh stem biomass weight. Fresh stem biomass of plants under salt stress and without salt treatment was recorded on a per plant basis at $14 \mathrm{~d}$ of salt stress. At that time, the susceptible check was completely dead. Stem biomass of salt-treated plants was lower than plants without being salt-treated (Fig. 9). Stem biomass was nearly normally distributed for plants without salt stress, whereas distribution was right-skewed for stem biomass of salt-stressed plants (Fig. 9). Stem biomass per plant varied from 0.86 to $2.53 \mathrm{~g}$, with an average of $1.64 \mathrm{~g}$ and an SD of 0.46 under non-stress conditions. Under salt treatment, stem biomass was in the range of 0.36 and $1.19 \mathrm{~g}$, with a mean of $0.71 \mathrm{~g}$ and an SD of 0.25 . Stem biomass was significantly different among the genotypes under salt stress (Fvalue $=16.88, P$ value $<0.0001)$ and without salt stress $(F$-value $=15.36, P$ value $<0.0001)$ (Table 2). 


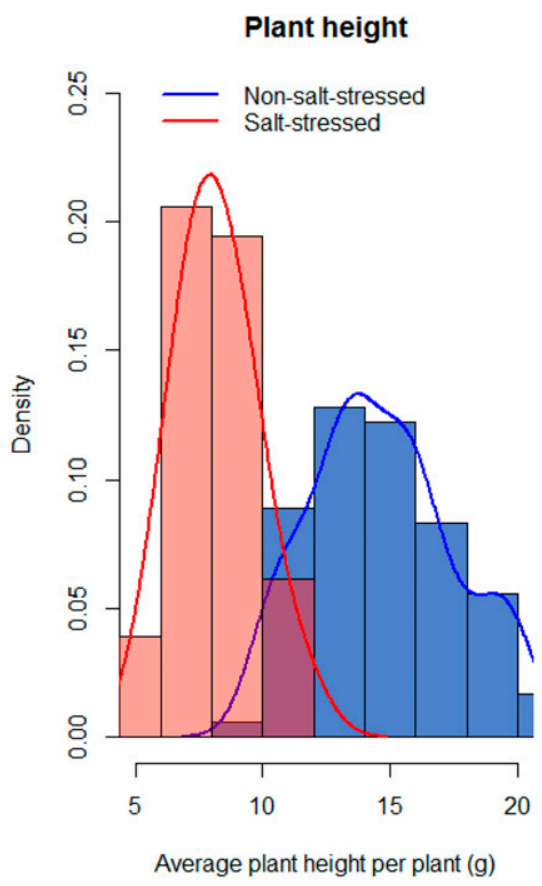

Fig. 7. Distributions of plant height of non-salt-stressed and salt-stressed plants, and relative salt tolerance for plant height.

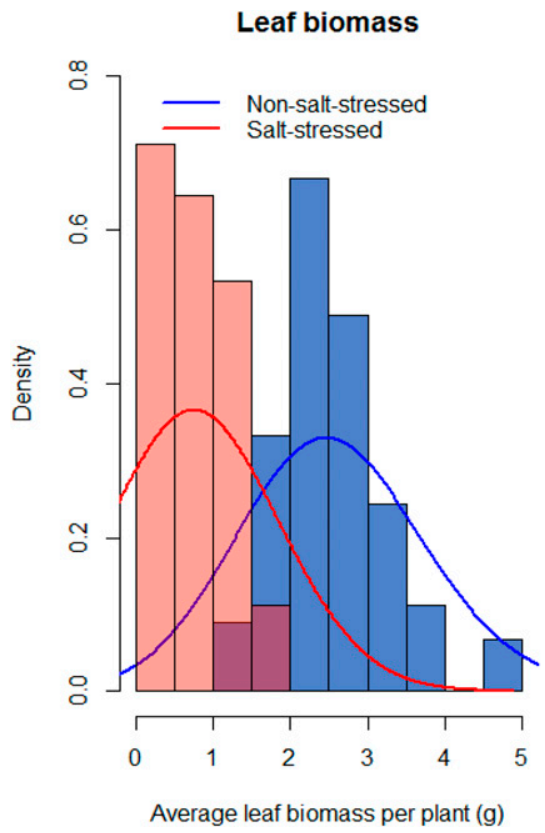

Fig. 8. Distributions of leaf biomass of non-salt-stressed and salt-stressed plants, and relative salt tolerance for leaf biomass.

RST for stem biomass varied from 0.18 to 0.68 , with a mean of 0.45 and an SD of 0.13 . Values of RST were about normally distributed (Fig. 9). RST for stem biomass was significantly different among the genotypes $($ F-value $=5.13, P$ value $<0.0001)($ Table 2$)$. Genotypes having the greatest RST for stem biomass were PI582551 (0.68), PI354865 (0.68), PI293586 (0.64), PI354835 (0.61), PI582368 (0.59), PI664524 (0.59), and PI354860 (0.58) (Supplemental Table 2). Lowest RST was recorded for PI582468 (0.38), PI349674 (0.37), PI229734 (0.35),
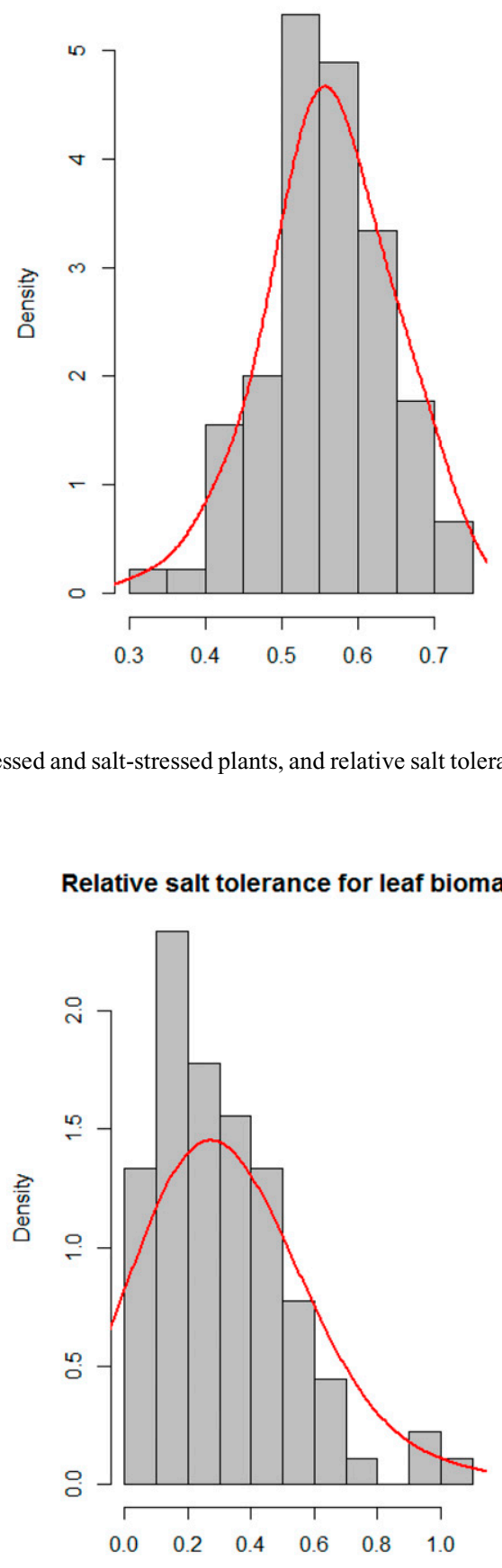

Relative salt tolerance for leaf biomass

PI582366 (0.34), PI582812 (0.30), PI291140 (0.25), PI582428 (0.22), and PI664515 (0.18) (Supplemental Table 2). Similar to plant height, none of the two controls were grouped into these extreme genotypes, indicating that stem biomass was not a good indicator for salt tolerance under this methodology.

Network analysis between traits and correlation analysis. Network analysis revealed existing pathways between number of dead plants, leaf injury scores, RST for chlorophyll content, chlorophyll content un- der salt stress, RST for leaf biomass, and leaf biomass under salt stress (Fig. 10). Pearson's correlation coefficients between number of dead plants and leaf injury score, number of dead plant and chlorophyll content under salt stress, and number of dead plants and RST for chlorophyll were $0.91,-0.81$, and -0.77 (Supplemental Table 3), respectively, indicating that salt stress caused sever leaf chlorosis, which resulted in leaf tissue damage and reduction in leaf matter, thus plant death. Another pathway defined by plant height under salt stress, plant height without salt stress, stem biomass under salt stress, and leaf biomass under salt stress was identified (Fig. 10). All parameters within the second network were related to non-stressed plants except for stem biomass and plant height, suggesting that phenotypic values obtained using these parameters were likely associated with plant morphology rather that response to salt tolerance. Since the second pathway was independent from the first one (Fig. 10), there was almost no correlation between the network defined by number of dead plants, leaf injury scores, RST for chlorophyll content, chlorophyll content under salt stress, RST for leaf biomass, and leaf biomass under salt stress, and that of plant height under salt stress, plant height without salt stress, stem biomass under salt stress, and leaf biomass under salt stress.

\section{Discussion}

Salt stress has been increasingly threating crop production globally (Flowers, 2004). Salinity affects more than 830 million hectares of croplands worldwide (Chaitanya et al., 2014). Shannon (1997) estimated a total of 1 to $60 \mathrm{t}$ of salt compound being annually added to cultivated areas, which has made salinity a growing concern to agriculture. The effects of salinity have been found to be more severe is semiarid regions, where cowpea is widely grown (Zhang et al., 2012). Providing farmers with genotypes that tolerate salt conditions better would be the most affordable way to limit the negative effects of salinity on crop production. Establishing a straightforward phenotyping strategy to select for salt-tolerant genotype will significantly help cowpea breeders to do so.

Since cowpea cultivation is predominant in developing countries in which there is a limited access to funding opportunities and facilities to set up hydroponic system to screen for salt tolerance in cowpea at seedling stage, providing cowpea scientists working in these areas with an easy-to-implement and cost-effective approach would help in enhancing breeding programs aiming at releasing salt-tolerant cowpea cultivars. In this current investigation, we developed a rapid screening methodology that can be followed and used by cowpea breeders when phenotyping for salt tolerance.

This research has been conducted in a controlled condition to limit potential effects of uncontrolled factors such as differences in soil fertility, transpiration, and root-soil 


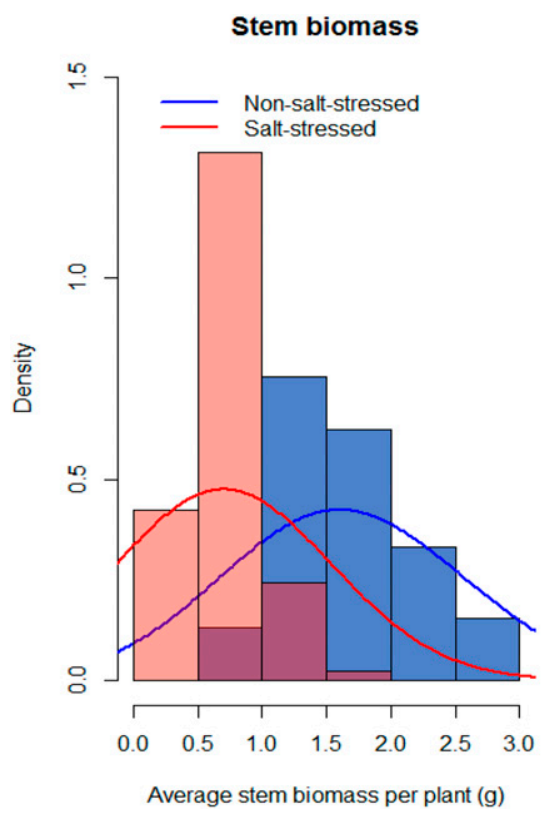

Relative salt tolerance for stem biomass

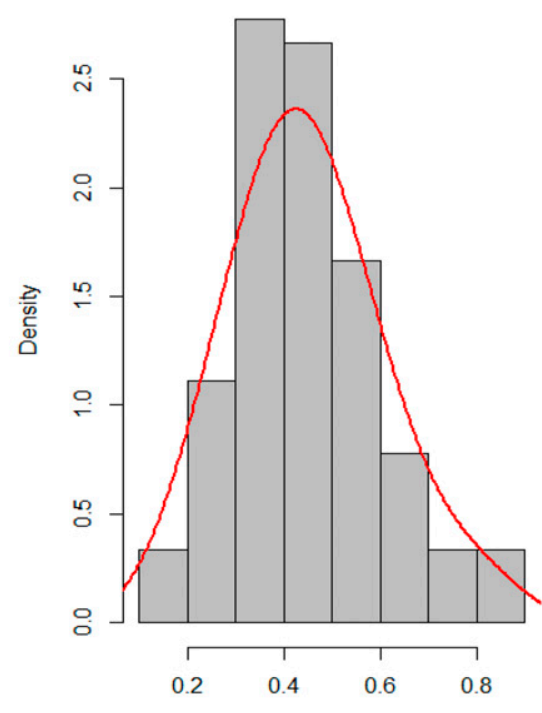

Fig. 9. Distributions of stem biomass of non-salt-stressed and salt-stressed plants, and relative salt tolerance for stem biomass.
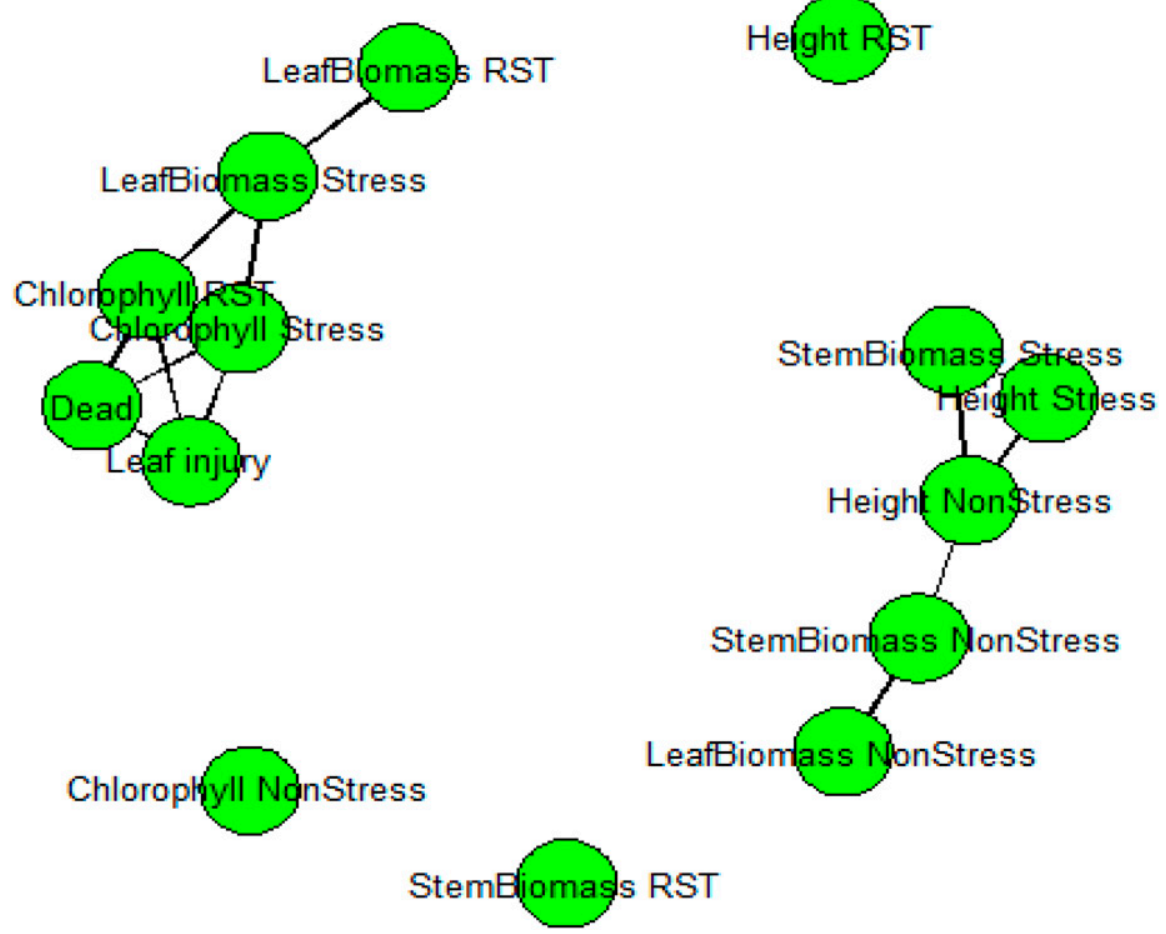

Fig. 10. Network analysis between traits evaluated under salt stress and non-salt conditions. Pathways were shown using solid lines when absolute value of Pearson's correlations was greater than 0.65 .

transmission that commonly occurred in field phenotyping (Pathan et al., 2007). Therefore, cowpea breeders can rapidly replicate promising investigations identifying good genotypes before conducting a field phenotyping with a fewer number of genotypes to screen, which could significantly limit the unexplained variation due to field conditions as previously stated. In addition, we have established easy-to-track phenotyping traits such as leaf score injury and leaf biomass for assessing salt tolerance, which does not require substantial costs to record, hence can be easily scaled up.

The current methodology has been validated by the use of two checks, PI582468 (salt-tolerant) and PI255774 (salt-sensitive), as previously reported (Ravelombola et al., 2017). Substantial discrepancy in aboveground traits between these genotypes was found even at $10 \mathrm{~d}$ of salt stress, suggesting that this approach can help differentiate a salt-tolerant genotype from a salt-sensitive one.

Replicating is a critical part of applied sciences and data from investigations that fail to be replicated cannot be used for further experiments in general. Therefore, to further validate our results, the two checks along with the two contrasting genotypes were repeated. Similar results from the previous screening were obtained in the replicated trial. The two salt-tolerant genotypes were fully green, whereas the two sensitive ones were almost dead at $11 \mathrm{~d}$ of salt stress as shown in Fig. 4, which further validated the methodology and the data from this investigation.

A total of 14 above-ground parameters was evaluated in this study. Mini et al. (2015) reported a high correlation between accumulation of salt ions and chlorophyll content in leaves of salt-stressed cowpea plants. Therefore, we suggested that chlorophyll content is a good indicator of salt tolerance in cowpea. Since analyzing ion contents within saltstressed cowpea leaves and roots could be expensive, measuring chlorophyll content could give a good approximation of salt tolerance. In fact, our results suggested that the two controls (PI582468 and PI255774) were significantly contrasting in terms of chlorophyll content under salt stress. In addition, Murillo-Amador et al. (2002) reported that ion exchange mechanisms played an imported role in conferring salt tolerance in cowpea. Praxedes et al. (2010) stated that salt-sensitive cowpea plants were not able to limit the uptake of $\mathrm{Na}+$ and $\mathrm{Cl}^{-}$under salt stress, which substantially lowered the chlorophyll content in the salt-sensitive genotypes as reported in this investigation.

A scoring-based scale for salt leaf injury $(1=$ green plant and $7=$ completely dead plant) was established to help cowpea scientists quantify the stay-green phenomenon under a prolonged period of salt stress. Establishing a straightforward scoring for salt injury has been proved to allow for a rapid screening for salt tolerance in other crops such as soybean [Glycine max (L.) Merr.] (Ledesma et al., 2016). In addition, path analysis from this investigation revealed significant correlations between number of dead plants, leaf injury scores, chlorophyll content of salt-stressed cowpea plants, and leaf biomass of salt stressed cowpea plants. Therefore, leaf injury score also could be used as a good indicator for salt tolerance in cowpea. Based on our experiment, we suggest that the criterion or the most "effective" parameters will depend on specific experiment for the salt treatment duration and salt stress level. At the end of the experiments, if there are large number of plants dead, then biomass may not be the best (accurate) parameter. If the plants are starting to die by the end of the study, visual scoring would be very effective. In this case, SPAD reading would be a great additional parameter to add.

The current methodology also allowed for clear distinction between the salt-tolerant genotype from the salt-sensitive one based on fresh leaf biomass weight under salt stress. 
El-Mashad and Mohamed (2012) reported that cowpea plants that were able to keep cell constituents from being extensively damaged by oxidative reaction occurring in leaf cells under salt stress were likely to withstand the stress, whereas those failing to prevent extensive lipid peroxidation occurring in leaves were highly susceptible to salt stress (Cavalcanti et al., 2004).

This research aimed at providing a streamlined protocol for salt tolerance phenotyping, which will have practical applications for cowpea breeding. The cowpea genotypes used as controls in this investigation can be freely accessed through the USDA Germplasm Resources Information Network website (https://npgsweb.ars-grin. gov/gringlobal/search.aspx) and available for orders and can be used for further references when selecting for salt-tolerant genotypes. Since the controls were freely available to everyone, we can expect that the present protocol can be used by other cowpea scientists contributing toward unraveling the genetics of salt tolerance in cowpea.

\section{Conclusion}

Phenotyping is one of the most challenging tasks in plant breeding. Being provided with a fast and accurate phenotyping strategy will allow for enhanced salt tolerance phenomics-related investigations, which is common in modern breeding. In this study, we conducted 14 above-ground traits for measuring salt tolerance in cowpea and found that the fewer number of dead plants per pot, high chlorophyll content, and less leaf injury scores were highly correlated and that each of the three parameters can be used as the criterion for salt tolerance evaluation in cowpea; thus, we developed a simple and costeffective salt tolerance methodology in cowpea, which is not yet available despite being important, to the best of our knowledge.

\section{Literature Cited}

Abeer, H., E.F. Abd_Allah, A.A. Alqarawi, and D. Egamberdieva. 2015. Induction of salt stress tolerance in cowpea [Vigna unguiculata (L.) Walp.] by arbuscular mycorrhizal fungi. Legume Res. 38:579-588.

Agbicodo, E. M., C. A. Fatokun, S. Muranaka, R.G.F. Visser, and C.G. van der Linden. 2009. Breeding drought tolerant cowpea: Constraints, accomplishments, and future prospects. Euphytica 167:353-370.

Allakhverdiev, S.I., A. Sakamoto, Y. Nishiyama, M. Inaba, and N. Murata. 2000. Ionic and osmotic effects of $\mathrm{NaCl}$-induced inactivation of photosystems I and II in Synechococcus $s p$. Plant Physiol. 123:1047-1056.

An, P., S. Inanaga, U. Kafkafi, A. Lux, and Y. Sugimoto. 2001. Different effect of humidity on growth and salt tolerance of two soybean cultivars. Biol. Plant. 44:405-410.

Ashebir, G., A. Mebeasilassie, and M. Manikanidan. 2013. The response of some cowpea (Vigna unguiculata (L.) Walp.) genotypes for salt stress during germination and seedling stage. J. Stress Physiol. Biochem. 9(4):57.

Ayers, R.S. and D.W. Westcot. 1985. Water quality for agriculture. FAO irrigation and drainage paper 29. Rev. 1. F. A. O. Rome.

Cavalcanti, F.R., J.T. Oliveira, A.S. MartinsMiranda, R.A. Viégas, and J.A. Silveira. 2004. Superoxide dismutase, catalase and peroxidase activities do not confer protection against oxidative damage in salt-stressed cowpea leaves. New Phytol. 163:563-571.

Chaitanya, K.V., C.R. Krishna, G.V. Ramana, and S.K.K. Beebi. 2014. Salinity stress and sustainable agriculture-A review. Agric. Rev. 35:34-41.

Dutta, P. and A.K. Bera. 2014. Effect of $\mathrm{NaCl}$ Salinity on seed germination and seedling growth of mungbean cultivars. Legume Res. 37:161-164.

El-Mashad, A.A.A. and H.I. Mohamed. 2012. Brassinolide alleviates salt stress and increases antioxidant activity of cowpea plants (Vigna sinensis). Protoplasma 249:625-635.

Fehr, W.R., C.E. Caviness, D.T. Burmood, and J.S. Pennington. 1971. Stage of development descriptions for soybeans, Glycine max (L.) Merrill. Crop Sci. 11:929-931.

Flowers, T.J. 2004. Improving crop salt tolerance. J. Expt. Bot. 55:307-319.

Frota, K.D.M.G., R.A.M. Soares, and J.A.G. Arêas. 2008. Chemical composition of cowpea (Vigna unguiculata L. Walp), BRS-Milênio cultivar. Food Sci. Technol. 28:470-476.

Läuchli, A. and U. Lüttge. 2002. Salinity: Environment-plants-molecules. Dordrecht, the Netherlands.

Ledesma, F., C. Lopez, D. Ortiz, P. Chen, K.L. Korth, T. Ishibashi, A. Zeng, M. Orazaly, and L. Florez-Palacios. 2016. A simple greenhouse method for screening salt tolerance in soybean. Crop Sci. 56:585-594.

Maas, E.V. and G.J. Hoffman. 1977. Crop salt tolerance-current assessment. J. Irrig. Drain. Div. 103:115-134.

Mini, M.L., M. Sathya, K. Arulvadivookarasi, K.S Jayachandran, and M. Anusuyadevi. 2015. Selection of salt tolerant cowpea genotypes based on salt tolerant indices of morphobiochemical traits. Curr. Trends Biotechnol. Pharm. 9:306-316.

Murillo-Amador, B., E. Troyo-Diéguez, R. LópezAguilar, A. López-Cortés, C.L. Tinoco-Ojanguri, H.G. Jones, and C. Kaya. 2002. Matching physiological traits and ion concentrations associated with salt stress in cowpea genotypes. Austral. J. Agr. Res. 53:1243.

Olufajo, O.O. 2012. Agronomic performance of improved cowpea varieties under natural infestation with Alectra vogelii (Benth.) in the northern Guinea savannah of Nigeria. Agr. Trop. Subtrop. 45:66-71.

Omami, E.N. and P.S. Hammes. 2006. Interactive effects of salinity and water stress on growth, leaf water relations, and gas exchange in amaranth (Amaranthus spp.). N. Z. J. Crop Hort. Sci. 34:33-44.

Parker, M.B., G.J. Gascho, and T.P. Gaines. 1983. Chloride toxicity of soybeans grown on Atlantic coast flatwoods soils. Agron. J. 75(3):439 443.

Pathan, M.S., J.D. Lee, J.G. Shannon, and H.T. Nguyen. 2007. Advances in molecular breeding toward drought and salt tolerant crops. Springer, the Netherlands.

Paul, S., A. Kundu, and A. Pal. 2011. Identification and validation of conserved microRNAs along with their differential expression in roots of Vigna unguiculata grown under salt stress. Plant Cell, Tissue and Organ Culture (PCTOC) 105:233-242.

Praxedes, S.C., C.F. De Lacerda, F.M. DaMatta, J.T. Prisco, and E. Gomes-Filho. 2010. Salt tolerance is associated with differences in ion accumulation, biomass allocation and photosynthesis in cowpea cultivars. J. Agron. Crop Sci. 196:193-204.

Ravelombola, W., A. Shi, Y. Weng, B. Mou, D. Motes, J. Clark, P. Chen, V. Srivastava, J. Qin, L. Dong, and W. Yang. 2017. Association analysis of salt tolerance in cowpea (Vigna unguiculata (L.) walp) at germination and seedling stages. Theor. Appl. Genet. 131:7991.

Rengasamy, P., D. Stevens, J. Kelly, M. McLaughlin, and M. Unkovich. 2006. Soil salinity and sodicity. CSIRO Publ., Collingwood, Australia.

Saad, F.F., A.A. Abd El-Mohsen, M.A. Abd, and I.H. Al-Soudan. 2014. Effective selection criteria for evaluating some barley crosses for water stress tolerance. Adv. Agr. Biol. 1(3): 112-123.

Shannon, M.C. 1997. Adaptation of plants to salinity. Adv. Agron. 60:75-120.

Singh, B.B., H.A. Ajeigbe, S.A. Tarawali, S. Fernandez-Rivera, and M. Abubakar. 2003. Improving the production and utilization of cowpea as food and fodder. Field Crops Res. 84:169-177.

Wallender, W.W. and K.K. Tanji. 2011. Agricultural salinity assessment and management. Am. Soc. Civ. Eng., Reston, VA.

Wilson, C., X. Liu, S.M. Lesch, and D.L. Suarez. 2006. Growth response of major US cowpea cultivars. I. Biomass accumulation and salt tolerance. HortScience 41:225-230.

Win, K.T. and A.Z. Oo. 2015. Genotypic difference in salinity tolerance during early vegetative growth of cowpea (Vigna unguiculata L. Walp.) from Myanmar. Biocatal. Agr. Biotechnol. 4:449-455.

Zahedi, S.M., N.A. Ansari, and M. Azizi. 2012. The study of the effect of salinity stress on the germination and the initial growth of cowpea (Vigna unguiculata L. Walp). Agr. Technol. Thail. 8:2353-2372.

Zhang, H.J., H.Z. Dong, W.J. Li, and D.M. Zhang. 2012. Effects of soil salinity and plant density on yield and leaf senescence of field-grown cotton. J. Agron. Crop Sci. 198:27-37. 


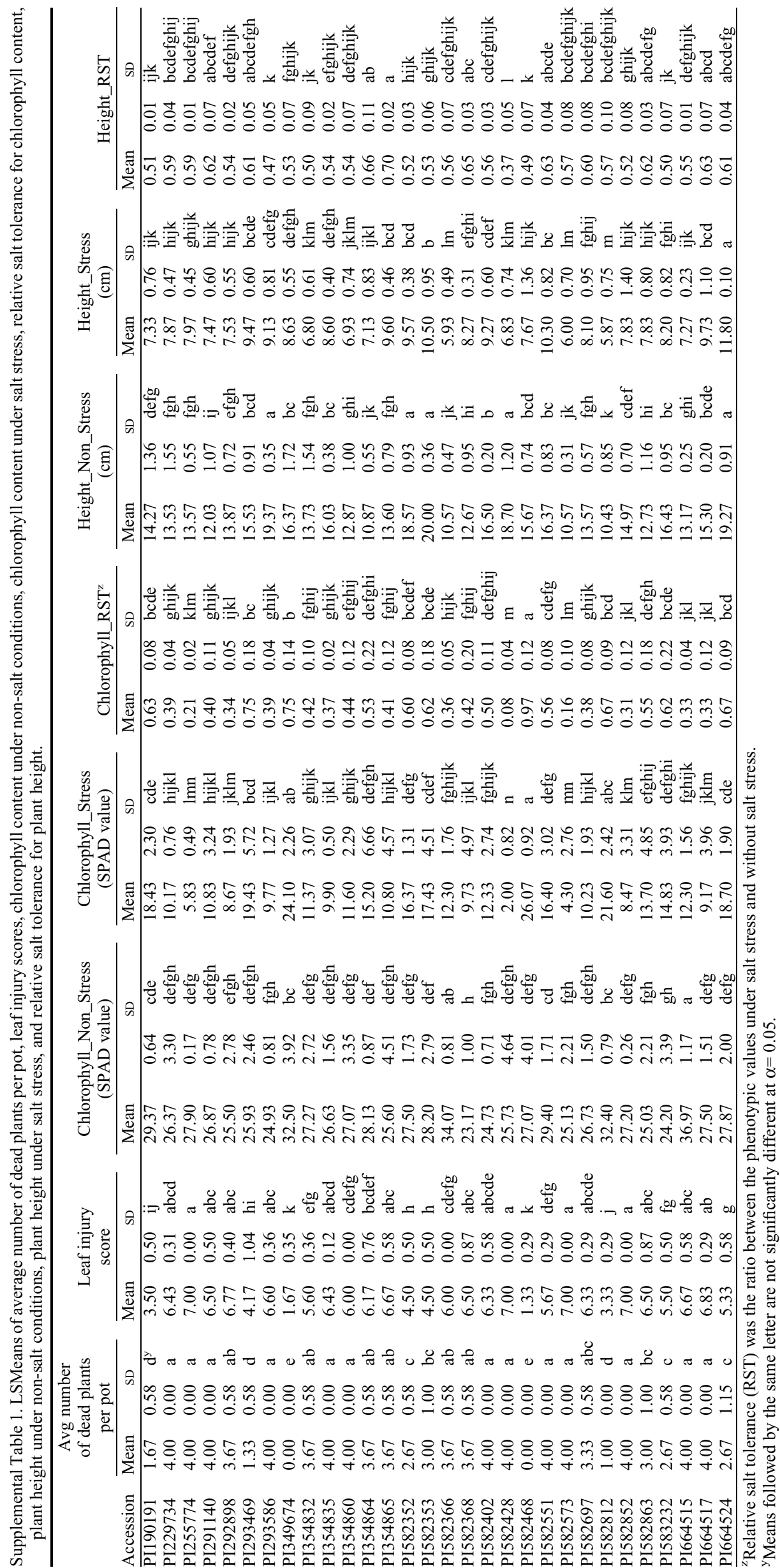

HortScience Vol. 54(8) August 2019 
Supplemental Table 2. LSMeans of leaf biomass under non-salt conditions, leaf biomass under salt stress, relative salt tolerance for leaf biomass, stem biomass under non-salt conditions, stem biomass under salt stress, and relative salt tolerance for stem biomass.

\begin{tabular}{|c|c|c|c|c|c|c|c|c|c|c|c|c|c|c|c|c|c|c|}
\hline \multirow[b]{2}{*}{ Accession } & \multicolumn{3}{|c|}{$\begin{array}{c}\text { Leaf } \\
\text { biomass_Non_Stress }(\mathrm{g})\end{array}$} & \multicolumn{3}{|c|}{$\begin{array}{c}\text { Leaf } \\
\text { biomass_Stress }(\mathrm{g}) \\
\end{array}$} & \multicolumn{3}{|c|}{ Leaf biomass_RST ${ }^{\mathrm{z}}$} & \multicolumn{3}{|c|}{$\begin{array}{c}\text { Stem } \\
\text { biomass_Non_Stress }(\mathrm{g})\end{array}$} & \multicolumn{3}{|c|}{$\begin{array}{c}\text { Stem } \\
\text { biomass_Stress }(\mathrm{g})\end{array}$} & \multicolumn{3}{|c|}{$\begin{array}{c}\text { Stem } \\
\text { biomass_RST (g) }\end{array}$} \\
\hline & Mean & & SD & Mean & & $\mathrm{SD}$ & Mean & & SD & Mean & & SD & Mean & $\mathrm{SD}$ & & Mean & & $\mathrm{SD}$ \\
\hline$\overline{\text { PI190191 }}$ & 2.33 & 0.24 & ghijk $^{y}$ & 1.04 & 0.31 & bcdefg & 0.45 & 0.17 & bcde & 1.54 & 0.20 & ijkl & 0.66 & 0.10 & ghijk & 0.43 & 0.03 & 1 \\
\hline PI229734 & 2.28 & 0.11 & hijkl & 0.24 & 0.09 & no & 0.10 & 0.04 & hi & 1.51 & 0.02 & ijkl & 0.53 & 0.04 & ijklm & 0.35 & 0.03 & $\mathrm{kl}$ \\
\hline PI255774 & 1.77 & 0.16 & $\operatorname{lm}$ & 0.15 & 0.03 & $\mathrm{o}$ & 0.08 & 0.03 & hi & 1.29 & 0.34 & $\mathrm{klm}$ & 0.52 & 0.14 & jklmn & 0.40 & 0.06 & $\mathrm{jkl}$ \\
\hline PI291140 & 2.49 & 0.23 & fghij & 0.83 & 0.13 & efghij & 0.34 & 0.04 & cdefg & 1.49 & 0.11 & $\mathrm{jkl}$ & 0.38 & 0.03 & $\mathrm{mn}$ & 0.25 & 0.03 & ijkl \\
\hline PI292898 & 2.63 & 0.18 & efghi & 0.56 & 0.12 & ijklmn & 0.22 & 0.06 & fghi & 1.40 & 0.28 & $\mathrm{jklm}$ & 0.76 & 0.15 & $\mathrm{fg}$ & 0.55 & 0.11 & hijk \\
\hline PI293469 & 1.78 & 0.11 & $\operatorname{lm}$ & 1.25 & 0.40 & abcd & 0.71 & 0.22 & $\mathrm{a}$ & 1.31 & 0.05 & $\mathrm{klm}$ & 0.66 & 0.04 & ghijk & 0.51 & 0.05 & ghijk \\
\hline PI293586 & 2.53 & 0.32 & fghij & 0.84 & 0.32 & efghij & 0.35 & 0.16 & cdefg & 1.89 & 0.21 & efgh & 1.19 & 0.08 & $a b$ & 0.64 & 0.10 & ghijk \\
\hline PI349674 & 2.33 & 0.35 & ghijk & 1.38 & 0.25 & $a b$ & 0.60 & 0.13 & $a b$ & 1.97 & 0.10 & defg & 0.73 & 0.07 & fgh & 0.37 & 0.04 & ghijk \\
\hline PI354832 & 3.37 & 0.54 & $\mathrm{bc}$ & 0.88 & 0.20 & defghij & 0.26 & 0.04 & efghi & 1.84 & 0.21 & fghi & 0.71 & 0.08 & fgh & 0.40 & 0.08 & ghij \\
\hline PI354835 & 1.51 & 0.36 & $\mathrm{~m}$ & 0.51 & 0.06 & jklmno & 0.35 & 0.09 & cdefg & 1.24 & 0.19 & $1 \mathrm{~m}$ & 0.74 & 0.09 & fg & 0.61 & 0.18 & fghij \\
\hline PI354860 & 2.11 & 0.30 & ijkl & 1.09 & 0.37 & bcdef & 0.51 & 0.13 & $a b c$ & 1.24 & 0.25 & $\operatorname{lm}$ & 0.69 & 0.07 & ghij & 0.58 & 0.18 & fghij \\
\hline PI354864 & 2.57 & 0.91 & fghij & 1.10 & 0.53 & bcdef & 0.54 & 0.46 & $a b c$ & 1.38 & 0.48 & $\mathrm{jklm}$ & 0.62 & 0.08 & ghijkl & 0.50 & 0.20 & fghij \\
\hline PI354865 & 2.48 & 0.26 & fghij & 0.35 & 0.11 & lmno & 0.15 & 0.06 & ghi & 1.60 & 0.20 & hijk & 1.07 & 0.13 & $\mathrm{bc}$ & 0.68 & 0.13 & fghi \\
\hline PI582352 & 2.83 & 0.15 & cdefg & 1.30 & 0.07 & $a b c$ & 0.46 & 0.02 & bcde & 2.28 & 0.12 & abcd & 0.88 & 0.12 & def & 0.39 & 0.07 & efghi \\
\hline PI582353 & 3.26 & 0.26 & bcd & 0.95 & 0.27 & cdefgh & 0.29 & 0.07 & defgh & 2.47 & 0.27 & $a b$ & 1.19 & 0.28 & $a b$ & 0.48 & 0.11 & efghi \\
\hline PI582366 & 2.15 & 0.26 & ijkl & 0.40 & 0.04 & klmno & 0.18 & 0.02 & fghi & 1.10 & 0.20 & $\mathrm{mn}$ & 0.36 & 0.07 & $\mathrm{n}$ & 0.34 & 0.15 & defghi \\
\hline PI582368 & 2.18 & 0.15 & ijkl & 0.36 & 0.04 & lmno & 0.17 & 0.01 & ghi & 1.11 & 0.01 & $\mathrm{mn}$ & 0.66 & 0.10 & ghijk & 0.59 & 0.09 & defghi \\
\hline PI582402 & 2.93 & 0.47 & cdef & 0.74 & 0.09 & fghijk & 0.25 & 0.03 & efghi & 1.66 & 0.07 & ghij & 0.73 & 0.07 & fgh & 0.44 & 0.04 & defghi \\
\hline PI582428 & 3.21 & 0.42 & bcd & 0.30 & 0.02 & mno & 0.09 & 0.01 & hi & 2.49 & 0.08 & $a b$ & 0.57 & 0.05 & hijkl & 0.22 & 0.02 & cdefgh \\
\hline PI582468 & 3.15 & 0.40 & bcde & 1.18 & 0.33 & abcde & 0.38 & 0.11 & cdef & 2.03 & 0.09 & cdef & 0.77 & 0.14 & efg & 0.38 & 0.08 & bcdefgh \\
\hline PI582551 & 2.17 & 0.16 & ijkl & 1.39 & 0.44 & $a b$ & 0.65 & 0.24 & $a b$ & 1.50 & 0.24 & $\mathrm{jkl}$ & 0.99 & 0.02 & $\mathrm{~cd}$ & 0.68 & 0.13 & bcdefgh \\
\hline PI582573 & 1.87 & 0.17 & $\mathrm{klm}$ & 0.24 & 0.13 & no & 0.12 & 0.07 & hi & 0.86 & 0.13 & $\mathrm{n}$ & 0.37 & 0.07 & $\mathrm{mn}$ & 0.44 & 0.13 & bcdefg \\
\hline PI582697 & 1.54 & 0.14 & $\mathrm{~m}$ & 0.69 & 0.08 & ghijkl & 0.45 & 0.07 & bcde & 1.30 & 0.25 & $\mathrm{klm}$ & 0.60 & 0.03 & ghijkl & 0.47 & 0.09 & abcdef \\
\hline PI582812 & 2.05 & 0.41 & $\mathrm{jk} l \mathrm{~m}$ & 0.93 & 0.18 & cdefghi & 0.47 & 0.15 & bcd & 1.22 & 0.16 & $\operatorname{lm}$ & 0.36 & 0.06 & $\mathrm{n}$ & 0.30 & 0.05 & abcde \\
\hline PI582852 & 2.34 & 0.23 & ghijk & 0.53 & 0.20 & jklmn & 0.22 & 0.07 & fghi & 1.60 & 0.31 & hijk & 0.70 & 0.23 & ghi & 0.44 & 0.10 & abcd \\
\hline PI582863 & 2.62 & 0.13 & efghi & 0.63 & 0.31 & hijklm & 0.24 & 0.11 & fghi & 1.23 & 0.20 & $\operatorname{lm}$ & 0.51 & 0.02 & klmn & 0.42 & 0.08 & abcd \\
\hline PI583232 & 2.73 & 0.50 & defgh & 0.91 & 0.16 & defghi & 0.34 & 0.08 & cdefg & 1.54 & 0.13 & ijkl & 0.64 & 0.08 & ghijk & 0.41 & 0.06 & $a b c$ \\
\hline PI664515 & 4.69 & 0.09 & $\mathrm{a}$ & 0.24 & 0.04 & no & 0.05 & 0.01 & $\mathrm{i}$ & 2.53 & 0.16 & $\mathrm{a}$ & 0.46 & 0.04 & $\operatorname{lmn}$ & 0.18 & 0.03 & $a b$ \\
\hline PI664517 & 3.50 & 0.30 & $\mathrm{~b}$ & 0.59 & 0.23 & hijklmn & 0.17 & 0.05 & ghi & 2.36 & 0.16 & $a b c$ & 0.94 & 0.13 & cde & 0.40 & 0.08 & $\mathrm{a}$ \\
\hline PI664524 & 3.19 & 0.39 & bcd & 1.50 & 0.16 & $\mathrm{a}$ & 0.48 & 0.09 & bcd & 2.19 & 0.17 & bcde & 1.28 & 0.03 & $\mathrm{a}$ & 0.59 & 0.05 & $\mathrm{a}$ \\
\hline
\end{tabular}

${ }^{\mathrm{z}}$ Relative salt tolerance (RST) was the ratio between the phenotypic values under salt stress and without salt stress.

${ }^{\mathrm{y}}$ Means followed by the same letter are not significantly different at $\alpha=0.05$. 


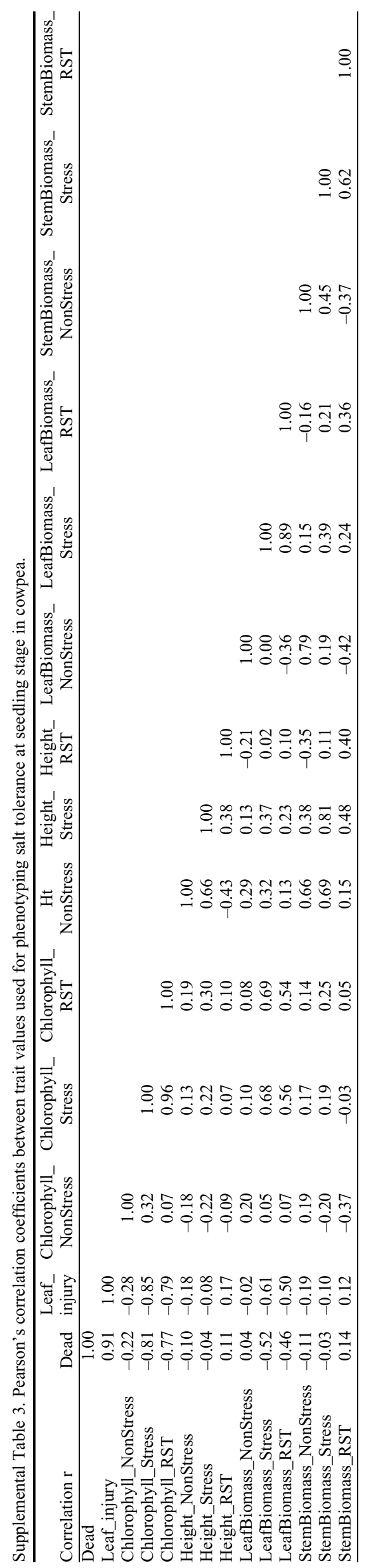

HortScience Vol. 54(8) August 2019 